\title{
Use of herpes virus amplicon vectors to study brain disorders
}

\author{
Rachael L. Neve ${ }^{1}$, Kim A. Neve ${ }^{2}$, Eric J. Nestler ${ }^{3}$, and William A. Carlezon, Jr. ${ }^{1}$ \\ BioTechniques 39:381-391 (September 2005)
}

\begin{abstract}
There is an enormous initiative to establish the genetic basis for disorders of brain function. Unfortunately, genetic intervention is not accomplished easily in the nervous system. One strategy is to engineer and deliver to neurons specialized viral vectors that carry a gene (or genes) of interest, thereby exploiting the natural ability of viruses to insert genetic material into cells. When delivered to brain cells, these vectors cause infected cells to increase the expression of the genes of interest. The ability to deliver genes into neurons in vitro and in vivo with herpes simplex virus (HSV) amplicon vectors has made it possible to carry out exactly these sorts of experiments. This technology has the potential to offer new insights into the etiology of a wide variety of neuropsychiatric disorders. We describe the use of HSV amplicon vectors to study Alzheimer disease, drug addiction, and depression, and discuss the considerations that enter into the use of these vectors both in vitro and in vivo. The HSV amplicon virus is a user-friendly vector for the delivery of genes into neurons that has come of age for the study of brain function.
\end{abstract}

\section{INTRODUCTION}

The delivery of recombinant genes into neurons is becoming an increasingly important strategy for answering questions about the molecular mechanisms of brain function and for understanding how these mechanisms go awry in disorders that affect the brain. Delineation of signal transduction pathways in neurons, of the molecular means by which neurotransmitters shape neuronal development and plasticity and of how trophic factors regulate neuronal health, will lead to insights into how defects in these pathways cause specific neurodegenerative and psychiatric diseases. An understanding of the mechanisms by which repeated exposure to drugs of abuse increases their stimulant and rewarding properties in animal models is likely to lead to new ways of treating addiction in humans.

The brain does not yield easily to genetic intervention, however. The terminally differentiated state of most neurons in the brain precludes the use of vectors that are dependent on cell replication for stable maintenance in the cell. In addition, the molecular mechanisms of specific brain disorders may be restricted to subsets of neurons at specific times during development and maturity. Therefore, strategies for manipulating gene expression in the brain must utilize vectors that can reside in postmitotic cells and that can be targeted both spatially and temporally in the nervous system. We will highlight in this Perspective the use of such a vector, herpes simplex virus (HSV), to study mechanisms underlying disorders of brain function.

\section{BIOLOGY OF HSV-1}

HSV-1 is a 150-kb double-stranded enveloped DNA virus that carries over 75 genes. HSV-1 has a wide host cell range and is capable of infecting most mammalian differentiated cell types. Natural HSV-1 infection is initiated when the virus breaches the epithelial cells of the skin or mucous membrane. Initial attachment of the enveloped particle to the plasma membrane is mediated by nonspecific charge interactions between viral envelope glycoproteins and glycosaminoglycan chains of proteoglycans on the cell surface (1). The virus recognizes specific cellular receptors, after which multiple viral glycoproteins mediate fusion of the virion envelope with the cell membrane (1). The virus travels by retrograde axonal transport from the site of its original entry to the nucleus of the neuron, into which viral DNA is released via a nuclear pore. At this point, the virus may begin a lytic infection resulting in viral replication or enter a latent state in which a family of latency-associated transcripts is expressed.

During lytic infection with HSV1 , viral genes are expressed in a temporally regulated sequence (2). Immediately following the release of the viral DNA into the nucleus, five genes encoding the immediate-early (IE) proteins ICPO, ICP4, ICP22, $I C P 27$, and ICP47 are transcribed, an operation that does not require viral protein synthesis. Two members of the IE gene product cascade, ICP4 and ICP27, regulate the expression of early and late genes that are required for viral replication (3). Viruses with deletions in essential genes such as ICP4 and ICP27 can propagate only in permissive host cells that provide the missing gene product in trans. Such deletion mutants provided the framework for the creation of the present-day replication-defective HSV-1 vectors described here.

\footnotetext{
${ }^{1}$ Harvard Medical School and McLean Hospital, Belmont, MA, ${ }^{2}$ VA Medical Center and Oregon Health \& Science University, Portland, OR, and ${ }^{3}$ The University of Texas Southwestern Medical Center, Dallas, TX, USA
} 


\section{AMPLICON HSV VECTORS}

Currently, there are two types of replication-defective HSV vectors. Genomic vectors are those in which the foreign DNA of interest is cloned into the viral genome itself. These vectors can be conceptualized as "crippled" viruses; the starting point is a competent virus from which one or more genes essential for the lytic cycle have been removed. A number of genes within the wild-type HSV-1 genome have been found to be dispensable for its growth in cells in vitro. This knowledge was used to create recombinant $\mathrm{HSV}-1$ viruses that could be used as vectors for gene transfer into cells (4). This type of genetically engineered genomic vector has been used by several investigators and is described in depth by Glorioso and collaborators $(3,5-7)$.

Conversely, amplicon vectors (Figure 1) can be conceptualized as "modular" viruses: the starting point is a plasmid (amplicon) to which minimal HSV-1 sequences are added, which allow it to be packaged into virus particles with the aid of a helper virus. The idea of the amplicon vector originated with the discovery of defective HSV-1 particles that appeared in, and interfered with, HSV-1 stocks that were passaged at high multiplicities of infection (MOI) (8-10). Examination of the genomes of these defective HSV-1 particles revealed that they carried only

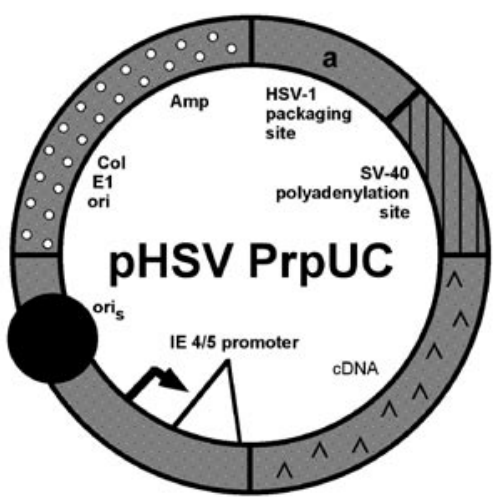

Figure 1. Diagram showing the elements of the basic amplicon cloning vector pHSVPrpUC. It consists of a ColE1 backbone, the HSV-1 "a" packaging site, and the HSV origin of replication $\left(\right.$ ori $\left._{s}\right)$. The HSV IE 4/5 promoter drives the expression of the inserted cDNA, from which is transcribed an RNA possessing the SV40 polyadenylation site. HSV, herpes simplex virus; SV40, simian virus 40 . a minimal subset of DNA sequences from the wild-type genome, which included an origin of DNA replication $\left(\mathrm{HSV}_{\text {ori }}\right)$ and a cleavage/packaging site (the "a" site). It was found that incorporation of these two sequences into a plasmid gave it the ability to replicate and be packaged into virus particles when it was introduced into cells that were superinfected with wild-type virus (which supplied HSV-1 replication and virion assembly functions in trans). The plasmid sequences that were packaged into virus particles consisted primarily of $150 \mathrm{~kb}$ concatemers of the original plasmid (8-10). This amplicon type of vector is now packaged with replication-defective helper virus or in a helper-free system.

Lim et al. (11) compared three replication-defective HSV-1 mutants [KOS strain $5 d l 1.2$, deleted in the ICP27 (IE2) gene; and strain 17 D30EBA and KOS strain $d l 120$, both deleted in the ICP4 (IE3) gene] for their usefulness as helper virus for packaging the amplicon vector pHSVlac, which uses the HSV-1 IE 4/5 promoter to regulate expression of the Escherichia coli lacZ gene. Historically, ICP4 mutants have been preferred because they express fewer HSV-1 genes under nonpermissive conditions than do ICP27 mutants. However, Lim et al. (11) found that the use of the IE2 mutant $5 d l 1.2$ yielded higher vector titers than did the use of the IE3 mutants. In addition, in their preparations, wild-type lytic virus arose at a greatly reduced rate when $5 d l 1.2$ was used in conjunction with 22 cells $\left(10^{-6}\right.$ in approximately $5 \%$ of the stocks), than when D30EBA was used together with M64A cells $\left(10^{-5}-10^{-4}\right)$. This difference in production of wildtype HSV-1 between the two systems is likely due to the facts that $5 d l 1.2$ is a more complete deletion than D30EBA, and that M64A cells have a substantial amount of flanking sequence that is homologous to that in the helper virus. It should be noted that we have never detected wild-type lytic virus in our preparations, which use the same helper virus and host cells.

An overview of the procedure for packaging HSV amplicon vector DNAs into virus is provided in Protocol 1. Full information, in the form of a detailed protocol, is provided as supplementary information available online at www.BioTechniques.com. The supplementary materials also contain an accompanying protocol that explains the process of titering HSV amplicon virus. Methods for titering the amplicon virus and for generating and titering helper stocks are also detailed by Lim and Neve (12). Methods for in vivo use of HSV vectors are described by Carlezon and Neve (13).

\section{ADVANTAGES AND LIMITATIONS OF HSV AMPLICON VECTORS}

Genomic and amplicon-defective HSV vectors have been used to manipulate neuronal physiology both in vitro and in vivo. These studies have highlighted both the promise and the limitations of these vectors. One of the chief advantages of the HSV amplicon vector relative to other vectors used for gene delivery into the brain (Table 1) is that cloning manipulations are relatively easy due to the small size $(5-10 \mathrm{~kb})$ of the plasmid. Additional advantages are that the amplicon plasmid accepts very large (theoretically up to 150 $\mathrm{kb}$ ) inserts and that HSV vectors have both a wide host range and a high transduction efficiency. A limitation is that production of amplicon vectors requires a co-propagated HSV-1 helper virus, resulting in viral stocks that are a mixture of helper and amplicon viruses. Moreover, in the past, nonspecific cytotoxic effects of defective amplicon vectors limited the amount of vector that could be used to infect cells. However, the achievement of a more favorable ratio of vector to helper and the virtual elimination of wild-type virus in the vector preparations (11) have minimized the cytotoxicity of present-day defective HSV-1 amplicon vectors. An additional improvement to the packaging procedure, the separation of the virus from cellular debris on a sucrose step gradient (HSV is too fragile to purify on a cesium chloride gradient), followed by a high-speed centrifugation to pellet the virus, has further reduced the cytotoxicity of the virus preparations. This step simultaneously removes toxic factors present in the crude cell lysates and enables 
Protocol 1. Outline of Protocol for Packaging Amplicon DNA into Virus

Day 1. Plate P0.

Day 2. Transfect amplicon vector DNA into PO cells.

Day 3. Superinfect PO with helper virus (5d/1.2). Plate P1.

Day 4. Harvest and freeze P0. Plate P2.

Day 5. Infect P1 with P0 lysate. Plate P3.

Day 6. Harvest P1. Infect P2 with P1 lysate.

Day 7. Harvest P2. Infect P3 with P2 lysate.

Day 8. Harvest and freeze P3.

Day 9. Purify P3 virus by sucrose gradient and store.

$\mathrm{P}$, passage.

concentration of the amplicon vector to titers exceeding $10^{8}$ infectious units (i.u.s) $/ \mathrm{mL}$.

The development of a helper virus-free packaging system for HSV amplicon vectors (14) has greatly reduced any lingering cytotoxicity in the preparations, although the helperfree system still yields relatively low titers of virus. This area of HSV vector engineering continues to undergo rapid improvement (15-21). For the moment, however, our laboratory and many others prefer packaging with helper virus because of the ease of the technology, the relatively high titers that can be achieved, and because of its virtual lack of toxicity despite the presence of helper virus.

One problem that has not yet been completely resolved for many viral vectors used in the brain is that of persistence of expression. Under some circumstances, transient transgene expression can be considered to be an advantage because it offers the opportunity to strengthen the association between a change in gene expression and a change in behavior (20-24). However, there are clearly instances in which more sustained expression is desirable or necessary. Published reports suggest that the problem of persistence of expression is not unsolvable. The use of a $9-\mathrm{kb}$ fragment of the tyrosine hydroxylase $(\mathrm{TH})$ promoter to drive reporter gene expression in an HSV amplicon vector resulted in prolonged gene expression in vivo (25), suggesting that neuronal, unlike viral, promoters in HSV-1 vectors have the potential to produce stable gene expression. Additionally, the development of hybrid amplicons that incorporate elements that allow autonomous replication of the episome (26) or that incorporate adenoassociated virus (AAV) elements for genomic integration of the amplicon (27-29) have resulted in vectors that support long-term gene expression both in vitro and in vivo. Most recently, a modified neurofilament gene promoter was shown to support long-term expression from an HSV amplicon vector in vivo in rat forebrain neurons (30); this same group showed that a preproenkephalinneurofilament chimeric promoter enabled long-term expression in vivo in rat striatum (31).

Despite the problems that remain with the HSV vector, it is a gene delivery system that is evolving into an important molecular tool to evaluate the biobehavioral significance of many genes expressed in brain. However, it should be noted that numerous alternative and increasingly user-friendly means of viral-mediated gene transfer into the brain are now available. The advantages and disadvantages of these alternative vectors relative to HSV vectors are summarized in Table 1.

The selection of the appropriate viral vector depends upon the goals of the experiment. HSV is an excellent vector when targeting neurons because it is naturally neurotropic. Ectopic expression of neuronal genes in nonneuronal cells might affect behavior when non-neurotropic viruses such as adenovirus are used. Additionally, although transgene expression with most HSV amplicon-based vectors is short-lived (2-5 days in vivo), this can be used to one's advantage to examine whether behavioral changes parallel changes in transgene expression. Such studies are difficult or impossible with vectors that cause persistent transgene expression. If long-term gene expression is critical, however, vectors such as those derived from adenoassociated virus or lentivirus would be more appropriate than most HSV ampliconbased vectors. It is likely, though, that the rapid pace of improvements in HSV amplicon vectors will soon yield vectors for which persistence of expression is commonplace.

\section{GENE DELIVERY INTO NEURONS IN VITRO AS A TOOL FOR ALZHEIMER DISEASE RESEARCH}

We have made extensive use of HSV vector infection of primary neurons in culture to study the molecular basis of Alzheimer disease. There are at least five major variables to consider when infecting primary neurons with HSV vectors. The first consideration concerns the amount of virus to add to the culture. When we titer our HSV vector stocks on PC12 cells, we titer them for the number of viruses expressing the transgene, rather than for the total number of virus particles. This makes it straightforward to determine how much virus to add to a primary neuronal culture. We have determined (32) that an MOI of 1.0 results in approximately $80 \%$ of the neurons expressing the transgene, while an MOI of 2.0 results in approximately $95 \%$ of the neurons expressing the transgene.

The second consideration is the ability to express multiple proteins within single neurons. Often, particularly in in situ studies of functional interactions between specific proteins, an experimental protocol depends on the coexpression of two or more genes in the same cell. While vectors have been described that express multiple gene products either using separate expression cassettes (33) or as multiple genes driven by the same promoter using an internal ribosome entry site (34), these methods do not allow the combinatorial flexibility afforded by multiple infection with separate vectors. To investigate the simultaneous coexpression of more than one virally introduced gene in primary cortical neurons, we infected cultures with two different HSV vectors and analyzed the proportion of singly and doubly infected cells (32). The vast majority of neurons expressed both gene products, with a smaller number expressing one or the other protein alone. Increasing the quantity of virus caused an increase in the proportion of double-labeled cells at the expense of singly labeled cells. Most recently, we have successfully carried out triple infections at an MOI of 2.0 for each vector and have shown that the majority of infected 
Table 1. Comparison of Viral Vectors Used to Study Brain Function

\begin{tabular}{|c|c|c|c|c|c|}
\hline & HSV & Adenovirus & AAV & Retrovirus & Lentivirus \\
\hline $\begin{array}{l}\text { Genomic } \\
\text { Integration }\end{array}$ & $\begin{array}{l}\text { Episomal, } \\
100 \%\end{array}$ & $\begin{array}{l}\text { Episomal, } \\
100 \%\end{array}$ & $\begin{array}{l}\text { Episomal, } \\
>90 \%\end{array}$ & Integrated & Integrated \\
\hline Cloning Capacity & $\begin{array}{l}150 \mathrm{~kb} \text { for amplicon; } \\
40 \mathrm{~kb} \text { for replication- } \\
\text { defective HSV }\end{array}$ & $\begin{array}{l}8 \text { kb for replication de- } \\
\text { fective AdV; } 30 \text { kb for } \\
\text { HC/gutless }\end{array}$ & $3.5-4.0 \mathrm{~kb}$ & $7-8 \mathrm{~kb}$ & $7-8 \mathrm{~kb}$ \\
\hline $\begin{array}{l}\text { Duration of } \\
\text { Expression In Vivo }\end{array}$ & $\begin{array}{l}\text { Days (amplicon) } \\
\text { to months } \\
\text { (replication-defective) }\end{array}$ & $\begin{array}{l}\text { First generation: } \\
10 \text { days to months; } \\
\text { gutted: long }\end{array}$ & $\begin{array}{l}\text { Long (2.5-6.0 } \\
\text { months) }\end{array}$ & Days to months & Long (>12 months) \\
\hline Disadvantages & $\begin{array}{l}\text { Occasional } \\
\text { cytotoxicity; strong } \\
\text { immune response } \\
\text { possible }\end{array}$ & $\begin{array}{l}\text { Severe inflammation } \\
\text { and immune response; } \\
\text { genetic manipulation } \\
\text { unwieldy }\end{array}$ & $\begin{array}{l}\text { Low cloning } \\
\text { capacity }\end{array}$ & $\begin{array}{l}\text { Insertional } \\
\text { mutagenesis }\end{array}$ & $\begin{array}{l}\text { Insertional } \\
\text { mutagenesis; } \\
\text { questionable safety; } \\
\text { possible germ-line } \\
\text { alterations }\end{array}$ \\
\hline
\end{tabular}

neurons expressed all three gene products (D.L. McPhie and R.L. Neve, unpublished data). Thus, co-infection with HSV vectors is an efficient way to obtain expression of multiple gene products within individual primary culture neurons.

The third variable is cytotoxicity of the HSV preparations. Measurement of toxicity using several different methods to assess apoptosis has revealed $(32,35)$ a low but dose-related level of toxicity in singly infected cultures, approximately $5 \%$ at an MOI of 1.0 . A comparison of single and doubleinfected cultures revealed a less than additive effect on cell death in the double-infected cultures. Thus, the toxicity of HSV preparations in cells in vitro is minimal. They do not show detectable toxicity in vivo (22).

A fourth variable is the time frame of expression following infection. Following infection of primary neuronal cultures with HSV vectors, expression of the transgene is detected within $2 \mathrm{~h}$ (36). We have found no diminution of expression up to $48 \mathrm{~h}$ post-infection (35). While we have not measured expression beyond $48 \mathrm{~h}$, in theory, the neurons should continue to express the transgene for the life of the culture.

Lastly, it is desirable to be able to coexpress with the transgene an in vivo marker such as green fluorescent protein (GFP). Such amplicon vectors have been developed by several laboratories, including that of Clark et al. (37) and have proved useful to mark neurons expressing the transgene for both in vitro and in vivo work.

HSV amplicon vectors expressing familial Alzheimer disease (FAD) mutants of presenilin 1 (PS1) and the amyloid precursor protein $(A P P)$ have been used to investigate the molecular basis of Alzheimer disease neuro- degeneration. Apoptotic pathways and DNA synthesis are activated in neurons in the brains of individuals with Alzheimer disease (38). Following reports that expression of FAD mutants of PS1 in cell lines can cause apoptosis or result in an increased susceptibility to apoptosis, we tested (35) whether expression of wild-type or FAD mutant PS1 in postmitotic cortical neurons results in DNA damage or apoptosis. DNA damage, chromatin condensation, and DNA fragmentation were assessed in primary cortical neurons infected with HSV vectors expressing wild-type PS1 or an FAD mutant of this gene, A246E, either 24 or $48 \mathrm{~h}$ after infection. At either time point, apoptosis was not detected in primary neurons infected with these vectors, suggesting that the reported enhancement of apoptosis by presenilins in dividing cells does not occur in primary neurons. 
While we did not find evidence for apoptosis in neurons expressing wild-type or FAD PS1 (35), we did find that cortical cultures infected with recombinant HSV vectors expressing APP showed a significant increase in the number of apoptotic cells and an increase in DNA fragmentation. These data suggested that transduction of primary neurons with HSV vectors expressing wild-type or FAD APP might yield clues to the molecular basis for Alzheimer disease neurodegeneration. Indeed, the expression of FAD mutants of APP in primary neurons in culture using HSV vectors causes DNA synthesis and apoptosis $(39,40)$. HSV vector-mediated expression of transgenes was used (40) to show that both the DNA synthesis and the apoptosis are mediated by the p21 activated kinase (PAK3) (41), which interacts with the carboxyl-terminus (C-terminus) of APP to activate these pathways. By using HSV vectors to coexpress a dominant negative mutant of PAK3 with FAD APP, McPhie et al. (40) showed that dominant negative PAK3 can inhibit FAD APPmediated DNA synthesis and neuronal apoptosis; this effect is abolished if the APP binding site is deleted from the dominant negative PAK3. Coexpression of HSV-FAD-APP and an HSV vector expressing a 26-amino acid peptide representing the PAK3 APP binding domain inhibited FAD APP-mediated DNA synthesis. These data suggest that binding of PAK3 to FAD APP is necessary for these neuronal pathways to be activated.

Pertussis toxin (PTX), which inactivates the heterotrimeric G-proteins $G_{0}$ and $G_{i}$, inhibits the DNA synthesis and apoptosis caused by FAD APP mutants; the DNA synthesis and apoptosis are rescued by co-infection with HSV expressing a PTX-insensitive $\mathrm{G}_{\mathrm{o}}$. FAD APP-mediated DNA synthesis precedes FAD APP-mediated apoptosis in neurons, and inhibition of neuronal entry into the cell cycle inhibits the apoptosis.

A second binding protein for the C-terminus of APP, APP-BP1 (42), was shown to drive the cell cycle through the S-M checkpoint (43). HSV-mediated APP-BP1 expression in primary neurons resulted in cell cycle entry and apoptosis $(43,44)$. APP-BP1 is the regulatory subunit of the activating enzyme for the small ubiquitin-like protein NEDD8 (43); we used HSV vectors expressing two dominant negative mutants in this pathway to show that this pathway is required for FAD APP-mediated neuronal cell cycle entry and apoptosis (44). Coexpression of FAD APP with a peptide representing the domain of APP-BP1 that binds to APP abolishes the ability of FAD APP to cause DNA synthesis and apoptosis, which suggests that interaction of FAD APP not only with PAK3 and $G_{0}$, but also with APP$\mathrm{BP} 1$, is necessary for the activation of these pathways.

Most recently, triplicate $\mathrm{HSV}$ vector infections have revealed that the coexpression of FAD APP and FAD PS1 causes neuronal apoptosis by a signaling pathway that is independent of the APP binding proteins PAK3 and APP-BP1 (D.L. McPhie and R.L. Neve, unpublished data). Thus, a series of experiments using HSV vectors to express specific transgenes in primary cultures in neurons has been used to dissect the components of an FAD APP-mediated signaling pathway that leads to neuronal cell cycle entry and consequent apoptosis.

\section{GENE DELIVERY INTO DIVIDING CELLS AS A TOOL FOR PHARMACOLOGICAL RESEARCH}

While we have emphasized here the use of HSV amplicon vectors to deliver genes into neurons, these vectors are also very useful for the delivery of genes into cell lines. HSV has a broad host range, so that HSV amplicon vectors have the ability to infect most cell lines. There are a number of advantages to infecting cell lines with HSV vectors rather than transfecting them with plasmid vectors. First, infection is less labor-intensive than transfection is. With HSV amplicon vectors, the virus is simply added to the medium that the cells are in. This stands in sharp contrast to transfection, in which plasmid DNAs must be preincubated with transfection reagent and which often necessitates replacement of the medium following transfection. Second, the time course of expression is faster following infection with HSV vectors than following transfection with plasmid DNA. The HSV vector transgene product is detected within $2 \mathrm{~h}$ post-infection, whereas one usually must wait for $24-36 \mathrm{~h}$ to perform experiments following transfection with a plasmid vector. Third, the percentage of infected cells is high, greater than $70 \%$ for an MOI of 1.0 . Fourth, there is greater consistency among experiments. A given MOI will yield consistent numbers of cells expressing the transgene whenever the infection is done. In contrast, the percentage of cells expressing the transgene will vary from experiment to experiment when transfections are done, necessitating co-transfection with a control plasmid so that betweenexperiment comparisons can be made. Finally, the expression of HSV vector transgenes tends to be high in dividing cells. We have detected robust transgene expression both from the HSV IE 4/5 promoter and from the cytomegalovirus (CMV) promoter in amplicon vectors. One caveat is that the duration of experiments using HSV vectors is limited by the doubling time of the cells. Because $\mathrm{HSV}$ is episomal, it does not replicate along with the cellular chromosomal DNA, so that the percentage of infected cells in a population decreases as the cells divide.

These features of HSV vectors have been exploited for pharmacological studies in cell lines. As noted in the next section, because the dopamine projection from the ventral tegmental area (VTA) of the midbrain to the nucleus accumbens (NAc) of the basal forebrain has been implicated in the rewarding effects of virtually all abused drugs, many studies on the molecular basis of addiction concern the regulation of cellular dopamine responsiveness. It is crucial that we understand the mechanisms of regulation of dopamine receptors because idiopathic or druginduced changes in the responsiveness of dopamine receptors are thought to be involved in the pathophysiology of drug abuse. The in vitro studies described below provide the basis for the types of in vivo studies delineated in the following section. Watts et al. (45) utilized this technology to 
identify the PTX-sensitive G-proteins responsible for rapid inhibition and delayed heterologous sensitization of adenylyl cyclase in neuroblastoma cells stably transfected with dopamine D2 receptors. HSV-mediated gene delivery was used to assess the ability of genetically engineered PTX-resistant Gproteins $\left(\mathrm{G}_{\alpha 1}{ }^{*}, \mathrm{G}_{\alpha 2}{ }^{*}, \mathrm{G}_{\alpha 3}{ }^{*}\right.$, and $\left.\mathrm{G}_{\alpha \mathrm{o}}{ }^{*}\right)$ to rescue inhibition and sensitization following PTX treatment. This study provided strong evidence that the D2 dopamine receptor couples to $G_{\alpha_{0}}$ in neuronal cells and that this coupling is responsible for the effects of D2 receptor activation on adenylyl cyclase activity. The same group (46) used HSV-mediated expression of $\mathrm{G}_{\alpha s}$-insensitive mutants of adenylyl cyclase type $\mathrm{V}$ in human embryonic kidney (HEK) 293 cells stably transfected with the D2L dopamine receptor to show that responsiveness to $G_{\alpha s}$ is required for the expression of heterologous sensitization. Schutzer et al. (47) examined the physiological effects of HSV-mediated transfer of constitutively activated $\mathrm{G}_{\mathrm{\alpha s}}$ to both cultured vascular smooth muscle cells and whole aortic tissue of adult animals to investigate adrenergic signal transduction in vascular tissue. These studies validate the use of HSV vector-mediated gene transfer as an effective tool to study pharmacology in dividing cells.

\section{GENE DELIVERY INTO NEURONS IN VIVO AS A TOOL FOR RESEARCH ON ADDICTION AND DEPRESSIVE STATES}

The use of any viral vector system for gene transfer studies in brain depends upon the dynamic interaction of several factors, including vector titer, injection volume, and the brain region targeted for study. Unfortunately, there is little information in the literature about how one, once in possession of a vector of interest, would embark upon an in vivo gene transfer study. We describe here some of the early experiments that we conducted to optimize procedures for our studies of the molecular biology of addiction and depression.

At present, the titers of our HSV amplicon vector preparations are on the order of $1-3 \times 10^{8}$ i.u. $/ \mathrm{mL}$. In our initial studies in brain (13), we evaluated gene transfer in the ventral tegmental area (VTA) using varied combinations of viral concentration and injection volumes. We started with $2.0 \mu \mathrm{L}$ microinjections (within a range of volumes often used for brain microinjections) of the virus preparations. For comparison, we also used 1.0 $\mu \mathrm{L}$ microinjections, and 2.0 or $1.0 \mu \mathrm{L}$ microinjections of the viruses diluted by $50 \%$. We found that the single most important factor for transgene expression in the VTA was injection volume: regardless of the vector titer, the sphere of transgene-expressing neurons in the VTA was substantially larger with $2.0 \mu \mathrm{L}$ microinjections than it was with $1.0 \mu \mathrm{L}$ microinjections. We proceeded with our behavioral studies using undiluted virus preparations because we found more transgeneexpressing neurons in rats that received the undiluted vector than in rats that received the $50 \%$ diluted vector; but overall, the effects attributable to titer were less striking than the effects attributable to injection volumes. This work suggests that, at some critical point specific for each type of vector, brain microinjections of higher titers simply cause more infections per cell rather than more cells infected. While toxicity of earlier generations of HSV may have been a problem in in vivo studies $(48,49)$, we have not detected any toxicity associated with the current generation of HSV amplicon vectors.

Another consideration is the targeted brain region itself. One of the most important current limitations of viral-mediated gene transfer is that it is difficult to design vectors that target specific subtypes of neurons [e.g., dopamine- or gamma-aminobutyric acid (GABA)-containing neurons]. This current limitation is less of a concern when the targeted brain regions are relatively homogenous in neuronal composition (e.g., the VTA) or when the transgenes are expressed ubiquitously in neurons [e.g., GluRs or cAMP response element binding protein (CREB)], but eventually it will be important to target specific neuronal populations in brain nuclei with more heterogeneous compositions. Ectopic transgene expression-expression of a transgene in a cell that normally does not express the gene-is a potential experimental confound in any studies in which only a certain percentage of the cells within a target nucleus express the gene under study. However, this limitation is not unlike that often encountered with transgenic mice, in which transgene expression can also be ectopic. As with any technology, advantages (the ability to alter expression of a single gene within a specific brain region in an adult animal that developed normally) must be weighed against disadvantages (limited neuronal specificity). When viral vectors that target specific neuronal populations become available, comparisons between the effects of less selective and more selective vectors will enable precise analyses of how specific neuronal types contribute to a given behavioral phenotype.

Viral-mediated gene transfer has been used to study complex motivational states associated with neuropsychiatric disorders such as addiction and depression. The use of viral vectors is particularly well suited to the study of addiction because exposure to drugs of abuse causes many changes in gene expression within the brain (50). This approach complements and extends the predominantly pharmacological approaches that have been used in addiction research, and in fact can be thought of as "genetic pharmacology." Viral vectors offer the capability to study individual changes in gene expression in discrete brain regions and, as such, it is possible to mimic certain aspects of the drug-exposed state without ever administering the drugs themselves. For example, repeated exposure to drugs of abuse such as cocaine, amphetamine, and opiates can cause "sensitization," a heightened sensitivity to their rewarding effects (51-53). The molecular mechanisms of sensitization are the focus of intense research because this process may contribute importantly to the development and maintenance of addiction (54). Because the dopamine projection from the VTA of the midbrain to the NAc of the basal forebrain has been implicated in the rewarding effects of virtually all abused drugs, many studies on the molecular basis of addiction are conducted within this circuitry. It 
has been demonstrated that repeated intermittent exposure to morphine or cocaine increases expression of the AMPA (glutamate) receptor subunit GluR1 within the VTA $(55,56)$. To directly test the hypothesis that this drug-induced molecular adaptation causes drug-induced behavioral adaptations (e.g., sensitization), we used viral vectors to elevate GluR1 levels within the VTA of rats not exposed previously to drugs. Rats with viral-mediated elevations in GluR1 expression within anterior portions of the VTA showed dramatic increases in sensitivity to the rewarding effects of morphine $(22,57)$. These data suggest that the behavioral consequences of repeated exposure to morphine are mimicked by gene transfer of GluR1 into the VTA and support a causal relation between previously disparate drug-induced molecular and behavioral adaptations.

Clues about the genes and intracellular mechanisms involved in depressive disorders have evolved from research on the molecular mechanisms of addiction. Exposure to psychostimulant drugs such as amphetamine or cocaine increases the function of the transcription factor CREB in regions including the NAc $(58,59)$. CREB regulates the expression of many genes (60), including that for dynorphin (61), an opioid peptide implicated in depressive states such as dysphoria (62). In rats, viral vector-mediated elevations of CREB in the NAc make low doses of cocaine aversive, and higher doses of cocaine less rewarding (22). In addition to producing these signs of anhedonia-a hallmark symptom of depression characterized by a diminished ability to experience rewarding stimuli as rewarding-elevations of CREB in the NAc also produce other signs of depression in animal models $(63,64)$. Antagonists of brain receptors for dynorphin ( $\kappa$ opioid receptors) eliminate the signs of aversion and depression $(23,63,65-67)$, suggesting that CREB-mediated induction of dynorphin contributes directly to these complex behavioral states.

Together, these types of "biobehavioral" studies demonstrate how viralmediated gene transfer offers a unique methodology with which to examine how temporally specific alterations in the expression of a single, localized gene product can lead to changes in behaviors that reflect complex motivational states. Moreover, they may help to identify intracellular pathways and alterations in gene expression that are potential targets for new generations of pharmacotherapies for addiction, depression, and perhaps other neuropsychiatric disorders.

\section{CONCLUSIONS}

We have demonstrated that HSV amplicon vectors have considerable utility for studying the molecular mechanisms of brain disorders. However, these vectors remain a work in progress. A number of methodological advances will greatly improve our ability to probe the molecular basis of brain function. First, stability of transgene expression must be achieved. Second, we must be able to achieve cell specificity of gene transfer by the use of targeted vectors that selectively infect particular cell types, cell-specific promoters, and routing via normal neuronal projections in the brain. Another set of hurdles arises from the complex etiology of most neuropsychiatric disease. The molecular mechanisms of different neuropsychiatric diseases may be restricted to subsets of neurons at specific times during development and maturity. Consequently, as noted above, optimal strategies for genetic intervention in the brain must utilize vectors that persist stably in postmitotic cells and that can be targeted both spatially and temporally in the nervous system. Nonetheless, despite these pending improvements in HSV amplicon vectors, they represent a gene delivery system that is evolving into an important molecular tool to evaluate the biobehavioral significance of many genes expressed in brain.

The recent rapid advancements in gene transfer technologies have raised hopes that central nervous system gene therapy, the introduction of genes into the brain to ameliorate neuropsychiatric diseases, is closer to reality. Indeed, there is a considerable body of work describing the feasibility of using alternative HSV vectors for such a purpose $(68,69)$. This exciting translational research demonstrates the utility of HSV vectors not only for doing basic research on brain disorders but also for using them to develop therapies for these disorders.

\section{ACKNOWLEDGMENTS}

This work was supported by National Institutes of Health (NIH) grants nos. AG12954 and AG021185 (to R.L.N.), and MH661872 (to R.L.N., E.J.N., and W.A.C.).

\section{COMPETING INTERESTS STATEMENT}

The authors declare no competing interests.

\section{REFERENCES}

1.Spear, P.G. 1993. Entry of alphaherpesviruses into cells. Semin. Virol. 4:167-180.

2.Honess, R.W. and B. Roizman. 1974 Regulation of herpes virus macromolecular synthesis. I. Cascade regulation of the synthesis of three groups of viral proteins. J. Virol. 14:8-19.

3.Fink, D.J., N.A. DeLuca, W.F. Goins, and J.C. Glorioso. 1996. Gene transfer to neurons using herpes simplex virus-based vectors. Annu. Rev. Neurosci. 19:265-287.

4.Roizman, B. and F.J. Jenkins. 1985. Genetic engineering of AOR1 genomes of large DNA virus. Science 229:1208-1214.

5.Simonato, M., R. Manservigi, P. Marconi, and J. Glorioso. 2000. Gene transfer into neurons for the molecular analysis of behaviour: focus on herpes simplex vectors. Trends Neurosci. 23:183-190.

6.Mata, M., J.C. Glorioso, and D.J. Fink. 2002. Targeted gene delivery to the nervous system using herpes simplex virus vectors. Physiol. Behav. 77:483-488.

7.Goins, W.F., D. Wolfe, D.M. Krisky, Q. Bai, E.A. Burton, D.J. Fink, and J.C. Glorioso. 2004. Delivery using herpes simplex virus: an overview. Methods Mol. Biol. 246:257-299.

8.Spaete, R.R. and N. Frenkel. 1982. The herpes simplex virus amplicon: a new eucaryotic defective-virus cloning-amplifying vector. Cell 30:295-304.

9.Spaete, R. and N. Frenkel. 1985. The herpes simplex virus amplicon: analyses of cis-acting replication functions. Proc. Natl. Acad. Sci. USA 82:694-698.

10.Stowe, N. and E. McMonagle. 1982 Propagation of foreign DNA sequences linked to a herpes simplex virus origin of replication, p. 199-204. In Y. Gluzman (Ed.), Eucaryotic Viral Vectors. CSH Laboratory Press, Cold Spring Harbor, NY. 
11.Lim, F., D. Hartley, P. Starr, P. Lang, S. Song, L. Yu, Y. Wang, and A.I. Geller. 1996. Generation of high-titer defective HSV-1 vectors using an IE 2 deletion mutant and quantitative study of expression in cultured cortical cells. BioTechniques 20:460-470.

12.Lim, F. and R.L. Neve. 1999. Generation of high-titer defective HSV-1 vectors, p. 4.13.14.13.17. In Current Protocols in Neuroscience. Greene Publishing Associates and WileyInterscience, New York.

13.Carlezon, W.A., Jr. and R.L. Neve. 2002. Viral-mediated gene transfer to study the behavioral correlates of CREB function in the nucleus accumbens of rats, p. 331-350. In J.Q. Wang (Ed.), Drugs of Abuse: Analysis of Neurological Effects, vol. 79 of the series Methods in Molecular Medicine (J.M. Walker, Series Ed.). Humana Press, Totowa, NJ.

14.Fraefel, C., S. Song, F. Lim, P. Lang, L. Yu, Y. Wang, P. Wild, and A.I. Geller. 1996. Helper virus-free transfer of herpes simplex virus type 1 plasmid vectors into neural cells. J. Virol. 70:7190-7197.

15.Sun, M., G.-R. Zhang, T. Yang, L. Yu, and A.I. Geller. 1999. Improved titers for helper virus-free herpes simplex virus type I plasmid vectors by optimization of the packaging protocol and addition of noninfectious herpes simplex virus-related particles (previral DNA replication enveloped particles) to the packaging procedure. Hum. Gene Ther. 10:20052011

16.Bowers, W.J., D.F. Howard, A.I. Brooks, M.W. Halterman, and H.J. Federoff. 2001. Expression of vhs and VP16 during HSV-1 helper virus-free amplicon packaging enhances titers. Gene Ther. 8:111-120.

17.Wang, X., G.R. Zhang, W. Zhang, and A.I. Geller. 2000. Fifty-one kilobase HSV-1 plasmid vector can be packaged using a helper virus-free system and supports expression in the rat brain. BioTechniques 28:102-107.

18.Saeki, Y., C. Fraefel, T. Ichikawa, X.O. Breakefield, and E.A. Chiocca. 2001. Improved helper virus-free packaging system for HSV amplicon vectors using an ICP27deleted, oversized HSV-1 DNA in a bacterial artificial chromosome. Mol. Ther. 3:591-601.

19.Tang, J., T. Yang, H.P. Ghosh, and A.I. Geller. 2001. Helper virus-free HSV-1 vectors packaged both in the presence of VSV G protein and in the absence of HSV-1 glycoprotein B support gene transfer into neurons in the rat striatum. J. Neuroviol. 7:548-555.

20.Sun, M., G.-R. Zhang, L. Kong, C. Holmes, X. Wang, W. Zhang, D.S. Goldstein, and A.I. Geller. 2003. Correction of a rat model of Parkinson's disease by coexpression of tyrosine hydroxylase and aromatic amino acid decarboxylase from a helper virus-free herpes simplex virus type I vector. Hum. Gene Ther. 14:415-424.

21.Ferrera, R., D. Cuchet, C. Zaupa, V. RevolGuyot, M. Ovize, and A.L. Epstein. 2005. Efficient and non-toxic gene transfer to cardiomyocytes using novel generation amplicon vectors derived from HSV-1. J. Mol. Cell. Cardiol. 38:219-223

22.Carlezon, W.A., Jr., V.A. Boundy, C.N. Haile, S.B. Lane, R.G. Kalb, R.L. Neve, and E.J. Nestler. 1997. Sensitization to morphine induced by viral-mediated gene transfer. Science 277:812-814.

23.Carlezon, W.A., Jr., J. Thome, V. Olson, S.B. Lane-Ladd, E.S. Brodkin, N. Hiroi, R.S. Duman, R.L. Neve, and E.J. Nestler. 1998. Regulation of cocaine reward by CREB. Science 282:2272-2275.

24.Kelz, M.B., J.S. Chen, W.A. Carlezon, Jr., K. Whisler, L. Gilden, A.M. Beckmann, C. Steffen, Y.J. Zhang, et al. 1999. Expression of the transcription factor $\Delta \mathrm{FosB}$ in the brain controls sensitivity to cocaine. Nature 401:272-276.

25.Jin, B.K., M. Belloni, B. Conti, H.J. Federoff, R. Starr, J.H. Son, H. Baker, and T.H. Joh. 1996. Prolonged in vivo gene expression by a tyrosine hydroxylase promoter in a defective herpes simplex virus amplicon vector. Hum. Gene Ther. 7:2015-2024.

26.Wang, S. and J. Vos. 1996. A hybrid herpesvirus infectious vector based on Epstein-Barr virus and herpes simplex virus type 1 for gene transfer into human cells in vitro and in vivo. J. Virol. 70:8422-8430.

27.Johnston, K.M., D. Jacoby, P. Pechan, C. Fraefel, P. Borghesani, D. Schuback, R.J. Dunn, F.I. Smith, and X.O. Breakefield. 1997. HSC/AAV hybrid amplicon vectors extend transgene expression in human glioma cells. Hum. Gene Ther. 8:359-370.

28.Fraefel, C., D.R. Jacoby, C. Lage, H. Hilderbrand, J.Y. Chou, F.W. Alt, X.O. Breakefield, and J.A. Majzoub. 1997. Gene transfer into hepatocytes mediated by helper virus free HSV/AAV hybrid vectors. Mol. Med. 3:813-825.

29.Constantini, L.C., D.R. Jacoby, S. Wang, C. Fraefel, X.O. Breakefield, and O. Isacson. 1999. Gene transfer to the nigrostriatal system by hybrid herpes simplex virus/adeno-associated virus amplicon vectors. Hum. Gene Ther. 10:2441-2494

30.Zhang, G., X. Wang, T. Yang, M. Sun, W. Zhang, Y. Wang, and A.I. Geller. 2000. A tyrosine hydroxylase-neurofilament chimeric promoter enhances long-term expression in rat forebrain neurons from helper virus-free HSV-1 vectors. Brain Res. Mol. Brain Res. 84:17-31.

31.Wang, X., L. Kong, G.R. Zhang, M. Sun, and A.I. Geller. 2004. A preproenkephalinneurofilament chimeric promoter in a helper virus-free herpes simplex virus vector enhances long-term expression in the rat striatum. Neurobiol. Dis. 16:596-603.

32.Coopersmith, R. and R.L. Neve. 1999. Expression of multiple proteins within single primary cortical neurons using a replication deficient HSV vector. BioTechniques 27:1156-1159.

33.Krisky, D.M., P.C. Marconi, T.J. Oligino, R.J. Rouse, D.J. Fink, J.B. Cohen, S.C. Watkins, and J.C. Glorioso. 1998. Development of herpes simplex replicationdefective multigene vectors for combination gene therapy applications. Gene Ther. 5:15171530.

34.Wagstaff, M.J., C.E. Lilley, J. Smith, M.J. Robinson, R.S. Coffin, and D.S. Latchman. 1998. Gene transfer using a disabled herpes virus vector containing the EMCV IRES al- lows multiple gene expression in vitro and in vivo. Gene Ther. 5:1566-1570.

35.Bursztajn, S., R. DeSouza, D.L. McPhie, S.A. Berman, J. Shioi, N.K. Robakis, and R.L. Neve. 1998. Overexpression in neurons of human presenilin-1 or a presenilin-1 familial Alzheimer disease mutant does not enhance apoptosis. J. Neurosci. 18:9790-9799.

36.Bahr, B.A., R.L. Neve, J. Sharp, A.I. Geller, and G. Lynch. 1994. Rapid and stable gene expression in hippocampal slice cultures from a defective HSV-1 vector. Brain Res. Mol Brain Res. 26:277-285.

37.Clark, M.S., T.J. Sexton, M. McClain, D. Root, R. Kohen, and J.F. Neumaier. 2002 Overexpression of 5-HT1B receptor in dorsa raphe nucleus using Herpes Simplex Virus gene transfer increases anxiety behavior af ter inescapable stress. J. Neurosci. 22:45504562

38.Herrup, K., R. Neve, S. Ackerman, and A. Copani. 2004. Divide and die: cell cycle events as triggers of nerve cell death. J. Neurosci. 24:9232-9239.

39.McPhie, D.L., T. Golde, C.B. Eckman, D. Yager, S.G. Younkin, and R.L. Neve. 2001 The $\beta$-secretase cleavage product of the amyloid precursor protein mediates neuronal apoptosis caused by familial Alzheimer's disease mutations. Brain Res. Mol. Brain Res. 97:103-113.

40.McPhie, D.L., R. Coopersmith, A. HinesPeralta, Y. Chen, K.J. Ivins, S.P. Manly, M.R. Kozlowski, K.A. Neve, and R.L. Neve. 2003. DNA synthesis and neuronal apoptosis caused by familial Alzheimer disease mutants of the amyloid precursor protein are mediated by the 21 activated kinase PAK3. J. Neurosci. 23:6914-6927.

41.Manser, E., C. Chong, Z.S. Zhao, T. Leung, G. Michael, C. Hall, and L. Lim. 1995. Molecular cloning of a new member of the p21-Cdc42/Rac-activated kinase (PAK) family. J. Biol. Chem. 270:25070-25078.

42.Chow, N., J.R. Korenberg, X.-N. Chen, and R.L. Neve. 1996. APP-BP1, a novel protein that binds to the carboxyl-terminal region of the amyloid precursor protein. J. Biol. Chem. 271:11339-11346.

43.Chen, Y., D.L. McPhie, J. Hirschberg, and R.L. Neve. 2000. The amyloid precursor protein-binding protein APP-BP1 drives the cell cycle through the S-M checkpoint and causes apoptosis in neurons. J. Biol. Chem. 275:8929-8935.

44.Chen, Y., W. Liu, D.L. McPhie, L. Hassinger, and R.L. Neve. 2003. APP-BP1 mediates APP-induced apoptosis and DNA synthesis and is increased in Alzheimer's disease brain. J. Cell Biol. 163:27-33.

45.Watts, V.J., B.L. Wiens, M.G. Cumbay, M.N. Vu, R.L. Neve, and K.A. Neve. 1998 Selective activation of $\mathrm{G}_{\alpha_{0}}$ by D2L dopamine receptors in NS20Y neuroblastoma cells. J. Neurosci. 18:8692-8699.

46.Watts, V.J., R. Taussig, R.L. Neve, and K.A Neve. 2001. Dopamine D2 receptor-induced heterologous sensitization of adenylyl cyclase requires $G_{\alpha s}$ : characterization of $G_{\alpha s}$-insensitive mutants of adenylyl cyclase V. Mol. Pharmacol. 60:1168-1172. 
47.Schutzer, W.E., V.J. Watts, J. Chapman, M.G. Cumbay, K.A. Neve, R.L. Neve, and S.L. Mader. 2000. Viral-mediated gene delivery of constitutively activated $\mathrm{G}_{\alpha \mathrm{s}}$ alters vasoreactivity. Clin. Exp. Pharmacol. Physiol. 27:9-13.

48.During, M.J., J.R. Naegele, K.L. O'Malley, and A.I. Geller. 1994. Long-term behavioral recovery in parkinsonian rats by an HSV vector expressing tyrosine hydroxylase. Science 266:1399-1403.

49.Isacson, O. 1995. Behavioral effects and gene delivery in a rat model of Parkinson's disease. Science 269:856-857.

50.Nestler, E.J. 2001. Molecular basis of longterm plasticity underlying addiction. Nat. Rev. Neurosci. 2:119-128.

51.Lett, B.T. 1989. Repeated exposures intensify rather than diminish the rewarding effects of amphetamine, morphine, and cocaine. Psychopharmacology (Berlin) 98:357-362.

52.Piazza, P.V., J.M. Deminiere, M. le Moal, and H. Simon. 1990. Stress- and pharmacologically-induced behavioral sensitization increases vulnerability to acquisition of amphetamine self-administration. Brain Res. 514:22-26.

53.Carlezon, W.A., Jr. and E.J. Nestler. 2002. Elevated levels of GluR1 in the midbrain: a trigger for sensitization to drugs of abuse? Trends Neurosci. 25:610-615.

54.Robinson, T.E. and K.C. Berridge. 2001. Incentive-sensitization and addiction. Addiction 96:103-114.

55.Fitzgerald, L.W., J. Ortiz, A.G. Hamedani, and E.J. Nestler. 1996. Drugs of abuse and stress increase the expression of GluR1 and NMDAR1 glutamate receptor subunits in the rat ventral tegmental area: common adaptations among cross-sensitizing agents. J. Neurosci. 16:274-282.

56.Churchill, L., C.J. Swanson, M. Urbine, and P.W. Kalivas. 1999. Repeated cocaine alters glutamate receptor subunit levels in the nucleus accumbens and ventral tegmental area of rats that develop behavioral sensitization. J. Neurochem. 72:2397-2403.

57.Carlezon, W.A., Jr., C.N. Haile, R. Coopersmith, Y. Hayashi, R. Malinow, R.L. Neve, and E.J. Nestler. 2000. Distinct sites of opiate reward and aversion within the midbrain identified by a herpes simplex virus vector expressing GluR1. J. Neurosci. 20:RC62, $1-5$.

58.Cole, R.L., C. Konradi, J. Douglass, and S.E. Hyman. 1995. Neuronal adaptation to amphetamine and dopamine: molecular mechanisms of prodynorphin gene regulation in rat striatum. Neuron 14:813-823.

59.Turgeon, S.M., A.E. Pollack, and J.S. Fink. 1997. Enhanced CREB phosphorylation and changes in c-Fos and FRA expression in striatum accompany amphetamine sensitization. Brain Res. 749:120-126.

60.Shaywitz, A.J. and M.E. Greenberg. 1999. CREB: a stimulus-induced transcription factor activated by a diverse array of extracellular signals. Annu. Rev. Biochem. 68:821-861.

61.Hurd, Y.L., E.E. Brown, J.M. Finlay, H.C. Fibiger, and C.R. Gerfen. 1992. Cocaine self-administration differentially alters mRNA expression of striatal peptides. Brain Res. Mol. Brain Res. 13:165-170.

62.Pfeiffer, A., V. Brantl, A. Herz, and H.M. Emrich. 1986. Psychotomimesis mediated by kappa opiate receptors. Science 233:774-776.

63.Pliakas, A.M., R. Carlson, R.L. Neve, C. Konradi, E.J. Nestler, and W.A. Carlezon, Jr. 2001. Altered responsiveness to cocaine and increased immobility in the forced swim test associated with elevated cAMP response element binding protein expression in nucleus accumbens. J. Neurosci. 21:7397-7403.

64.Barrot, M., J.D. Olivier, L.I. Perrotti, R.J. DiLeone, O. Berton, A.J. Eisch, S. Impey, D.R. Storm, et al. 2002. CREB activity in the nucleus accumbens shell controls gating of behavioral responses to emotional stimuli. Proc. Natl. Acad. Sci. USA 99:11435-11440.

65.Newton, S.S., J. Thome, T.L. Wallace, Y. Shirayama, L. Schlesinger, N. Sakai, J. Chen, R. Neve, et al. 2002. Inhibition of cAMP response element-binding protein or dynorphin in the nucleus accumbens produces an antidepressant-like effect. J. Neurosci. 22:10883-10890.

66.Mague, S.D., A.M. Pliakas, M.S. Todtenkope, H.C. Tomasiewicz, Y. Zhang, W.C. Stevene, Jr., R.M. Jones, P.S. Portoghese, and W.A. Carlezon, Jr. 2003. Antidepressant-like effects of kappa opioid receptor antagonists in the forced swim test in rats. J. Pharmacol. Exp. Ther. 305:323-330.

67. Todtenkopf, M.S., J.F. Marcus, P.S. Portoghese, and W.A. Carlezon, Jr. 2004. Effects of kappa-opioid receptor ligands on intracranial self-stimulation in rats. Psychopharmacology (Berlin) 172:463-470.

68.Glorioso, J.C. and D.J. Fink. 2004. Herpes vector-mediated gene transfer in treatment of diseases of the nervous system. Annu. Rev. Microbiol. 58:253-271.

69.Yenari, M.A. and R.M. Sapolsky. 2005. Gene therapy in neurological disease. Methods Mol. Med. 104:75-88.

Address correspondence to:

Rachael L. Neve

McLean Hospital MRC 223

115 Mill Street

Belmont, MA 02478

e-mail:neve@helix.mgh.harvard.edu

To purchase reprints

of this article, contact

apfeffer@BioTechniques.com 